\title{
Study of the role of hysteroscopy with dilation and curettage in post- menopausal bleeding: a cross sectional study
}

\author{
Atul Padmawar*, Ankita Khande \\ Department of Obstetrics and Gynecology, Shri Vasantrao Naik Government Medical College, Yavatmal, \\ Maharashtra, India \\ Received: 13 February 2020 \\ Accepted: 06 March 2020 \\ *Correspondence: \\ Dr. Atul Padmawar, \\ E-mail: drpradiprao@gmail.com \\ Copyright: ( $)$ the author(s), publisher and licensee Medip Academy. This is an open-access article distributed under \\ the terms of the Creative Commons Attribution Non-Commercial License, which permits unrestricted non-commercial \\ use, distribution, and reproduction in any medium, provided the original work is properly cited.
}

\begin{abstract}
Background: Abnormal uterine bleeding is defined as any type of bleeding in which the duration, frequency or amount is excessive for an individual patient. Hysteroscopy has ushered a new era in the evaluation of abnormal uterine bleeding. With this background, we conducted a study to find the role of hysteroscopy with dilation and curettage in post-menopausal bleeding.

Methods: It was an observational study conducted in the department of obstetrics and gynecology of a tertiary care hospital in Maharashtra. Post-menopausal patients with abnormal uterine bleeding, admitted in the period of March 2018 to September 2019 were included in the study. A pretested and predesigned questionnaire was used to collect the data. Hysteroscopy with dilation and curettage was done and samples were sent for histopathology.

Results: Bleeding was present in all the 30 cases. About $33.33 \%$ had pain abdomen, $56.67 \%$ had hot flushes, $10.00 \%$ had mass and $10 \%$ had other symptoms in the present study. The sensitivity, specificity, positive predictive value, negative predictive value and diagnostic accuracy of hysteroscopy in diagnosing malignancy was $75 \%, 96.15 \%, 75 \%$, $96.15 \%$ and $93.33 \%$ respectively.

Conclusions: To conclude the most common cause of abnormal uterine bleeding in post-menopausal women in our study was polyp. The sensitivity and specificity of the hysteroscopy in diagnosing the malignant lesions is $75 \%$ and $96.15 \%$ respectively which corroborated with other study findings. Hysteroscopy with dilation and curettage is better alternative to hysterectomy and biopsy in most of the cases.
\end{abstract}

Keywords: Dilation and curettage, Hysteroscopy, Post-menopausal bleeding

\section{INTRODUCTION}

Abnormal uterine bleeding is defined as any type of bleeding in which the duration, frequency or amount is excessive for an individual patient. ${ }^{1}$ In normal to 12 -week size uterus, the cause of abnormal bleeding often remains obscure. Goals of clinical management are primarily dependent upon attaining a correct etiological diagnosis. The history, physical examination and pelvic examination attempt to determine the site of the bleeding and its source. Information gathered from this will suggest what direction the investigation would take and the treatment modality. Ultrasonography clearly depicts the uterine contour, any lesion in the myometrium like fibroid and the status of the ovary, but fails to provide adequate information regarding the endometrium. The endometrial pathology like small submucous fibroid, endometrial hyperplasia is missed sometimes by ultrasound. ${ }^{2}$ Dilatation and curettage is a blind procedure done without knowing the exact location of the lesion or the pathology of the endometrium and the endometrium has to be sent to the pathologist to study histological patterns and for the report. ${ }^{3}$ Hysteroscopy has ushered a new era in the evaluation of abnormal uterine bleeding. By direct 
visualization of the uterine cavity it is able to pin point the aetiology in majority of the cases. It can accurately detect endometrial hyperplasia and aids in the early diagnosis of endometrial carcinoma and uterine polyps. The judicious use of hysteroscopy to manage this medical entity adds a new dimension in handling this oftenperplexing problem. ${ }^{4}$

\section{METHODS}

It was a observational study conducted in the department of obstetrics and gynecology of a tertiary care hospital in Maharashtra. Post-menopausal patients with abnormal uterine bleeding, admitted in the period of March 2018 to September 2019 were included in the study. Women with abnormal uterine bleeding due to injuries of the female reproductive tract, not willing to participate in the study, already diagnosed cases of carcinoma were excluded and omen of hormone replacement therapy were excluded from the study. Study included 30 cases of postmenopausal uterine bleeding admitted under our department during the study period. Since, we have limitation of duration of the study so we included most of the cases in the study.

Data was collected using a pretested and predesigned questionnaire. The questionnaire consisted of sociodemographic factors like age, occupation, educational status, socioeconomic status etc. It also included the general physical examination findings, systemic examination findings of the study subjects. Associated morbidities like diabetes, hypertension, IHD and tuberculosis were also noted. The socioeconomic status was classified into classes based on the modified BG Prasad classification for the year 20195. The hemoglobin values were categorized based on the world health organization guidelines for classification of anaemia6. Further, we also noted the chief complaints and did a detailed gynecological examination of the subjects. Appropriate investigations were done before the start of the procedure.

Hysteroscopy was video-assisted and carried out with normal saline solution used as liquid distension medium; a 5-mm sheathed hysteroscope, with a working channel, was used for each examination. After hysteroscopic inspection, an endometrial sampling targeted under vision was performed by mechanical or electrosurgical instrumentation. When extensive features of hyperplastic or neoplastic growth were observed, we combined a blind sampling procedure with dilatation- curettage. All cases diagnosed with carcinoma histopathologically were referred to an onco-surgeon for further evaluation.

\section{Statistical analysis}

The data was collected, compiled and analyzed using EPI info (version 7.2). The qualitative variables were expressed in terms of percentages. The quantitative variables were both categorized and expressed in terms of percentages or in terms of mean and standard deviations. The diagnostic performance was expressed in terms of sensitivity, specificity, positive predictive value, negative predictive value and diagnostic accuracy. Histopathology was considered gold standard for the diagnosis. All tables were graphically represented.

\section{Statistical analysis}

All analysis was 2 tailed and the significance level was set at 0.05 .

\section{RESULTS}

Study included 30 study subjects.

Table 1: Demographic characteristics of the study subjects.

\begin{tabular}{|l|l|l|}
\hline Age group & Frequency & Percentage \\
\hline 40 to 50 & 2 & $6.67 \%$ \\
\hline 50 to 60 & 5 & $16.67 \%$ \\
\hline 60 to 70 & 14 & $46.66 \%$ \\
\hline$>70$ & 9 & $30.00 \%$ \\
\hline Educational status & & \\
\hline Illiterate & 4 & $13.33 \%$ \\
\hline Primary school & 7 & $23.34 \%$ \\
\hline Secondary school & 10 & $33.34 \%$ \\
\hline Matriculation & 4 & $13.33 \%$ \\
\hline Post matriculation & 3 & $10.00 \%$ \\
\hline Bachelors & 1 & $3.33 \%$ \\
\hline Post graduate and above & 1 & $3.33 \%$ \\
\hline Socio economic status & & \\
\hline Class 1 & 1 & $3.33 \%$ \\
\hline Class 2 & 6 & $20.00 \%$ \\
\hline Class 3 & 9 & $30.00 \%$ \\
\hline Class 4 & 6 & $20.00 \%$ \\
\hline Class 5 & 8 & $26.67 \%$ \\
\hline Religion & & \\
\hline Hindu & 20 & $66.66 \%$ \\
\hline Muslim & 5 & $16.67 \%$ \\
\hline Others & 5 & $16.67 \%$ \\
\hline & & \\
\hline
\end{tabular}

Majority of them were in the age range of 60 to 70 years, were Hindus, were educated up to secondary school and were class 3 according to BG Prasad classification of socio-economic status (Table 1).

Figure 1 shows bleeding was present in all the 30 cases. About $33.33 \%$ had pain abdomen, $56.67 \%$ had hot flushes, $10.00 \%$ had mass and $10 \%$ had other symptoms in the present study.

All the cases which were normal on hysteroscopy were having a tropic endometrium, all polyps and myomas were histopathologically the same. Among 5 cases of hyperplasia one case had complex or atypical hyperplasia and four cases had simple hyperplasia. Among the three 
cases diagnosed by hysteroscopy one case had complex hyperplasia and two cases were diagnosed to have carcinoma. Based on the hysteroscopic findings, $10 \%$ were normal, $40 \%$ were polyp, $23.33 \%$ had myoma, $16.67 \%$ had hyperplasia and $10 \%$ had carcinoma in the present study. Based on the histopathological diagnosis, $40 \%$ were polyp, $23.33 \%$ were myoma, $13.33 \%$ were simple hyperplasia, $6.67 \%$ had complex hyperplasia, $6.67 \%$ had carcinoma and $10 \%$ had atrophy of endometrium (Table 2).

The sensitivity, specificity, positive predictive value, negative predictive value and diagnostic accuracy of hysteroscopy in diagnosing malignancy was 75\%, $96.15 \%, 75 \%, 96.15 \%$ and $93.33 \%$ respectively (Table $3)$.

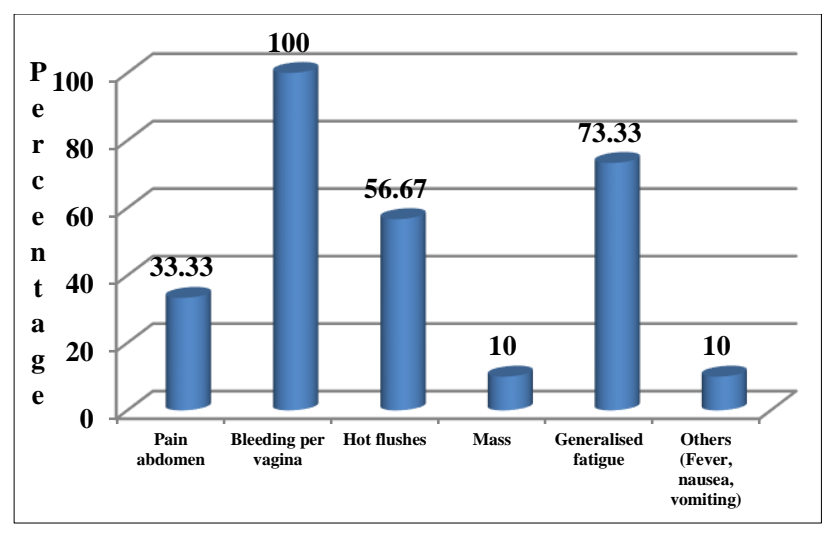

Figure 1: Distribution of the study subjects based on the chief complaints $(n=30)$.

Table 2: Histopathological correlation with hysteroscopy findings.

\begin{tabular}{|lllllll|}
\hline $\begin{array}{l}\text { Hysteroscopy } \\
\text { findings }\end{array}$ & Holyp & Myoma & $\begin{array}{l}\text { Simple } \\
\text { hyperplasia }\end{array}$ & $\begin{array}{l}\text { Complex hyperplasia/ } \\
\text { atypical }\end{array}$ & Carcinoma & $\begin{array}{l}\text { Atrophy/not } \\
\text { satisfactory }\end{array}$ \\
\hline Normal & 0 & 0 & 0 & 0 & 0 & 3 \\
\hline Polyp & 12 & 0 & 0 & 0 & 0 & 0 \\
\hline Myoma & 0 & 7 & 0 & 0 & 0 & 0 \\
\hline Hyperplasia & 0 & 0 & 4 & 1 & 0 & 0 \\
\hline Carcinoma & 0 & 0 & 0 & 1 & 2 & 0 \\
\hline
\end{tabular}

Table 3: Diagnostic performance of hysteroscopy with histopathology.

\begin{tabular}{|llll|}
\hline \multirow{2}{*}{ Hysteroscopy findings } & \multicolumn{2}{l|}{ Histopathological diagnosis } & Total \\
\cline { 2 - 4 } & Positive & Negative & 4 \\
\hline Positive & 3 & 1 & 26 \\
\hline Negative & 1 & 25 & 30 \\
\hline Total & 4 & 26 & \\
\hline Diagnostic performance & & & \\
\hline Sensitivity & $75 \%$ & & \\
\hline Specificity & $96.15 \%$ & & \\
\hline Positive predictive value & $75 \%$ & & \\
\hline Negative predictive value & $96.15 \%$ & & \\
\hline Diagnostic accuracy & $93.33 \%$ & & \\
\hline
\end{tabular}

\section{DISCUSSION}

Hysteroscopy is a novel method in which has been used to diagnose and treat the cause of abnormal uterine bleeding in post-menopausal women. With this basic background we conducted a study to understand the role of hysteroscopy in our patients with post-menopausal bleeding.

All the cases which were normal on hysteroscopy were having a tropic endometrium, all polyps and myomas were histopathologically the same. Among 5 cases of hyperplasia one case had complex or atypical hyperplasia and four cases had simple hyperplasia. Among the three cases diagnosed by hysteroscopy one case had complex hyperplasia and two cases were diagnosed to have carcinoma. Elfayomy A et al, reported that endometrial polyps were the most common hysteroscopic pathologies observed in 25 cases $(30.1 \%)$, while endometrial hyperplasia and carcinoma diagnosed visually by the hysteroscopes in $18(21.7 \%)$ and 11 cases (13.3\%), respectively. ${ }^{7}$ The hysteroscopic findings and the histological diagnoses were compared in 83 cases. Of note, hyperplastic endometrium was confirmed by histology in 23 (27.8\%), 13 cases had been suspected by the hysteroscope, the other 10 cases were not suspected during visual diagnosis of the uterine cavity. On the other 
hand, the hysteroscopic findings were not suspicious for malignancy in seven cases proved by histological examination. All six myomas at hysteroscopy were confirmed by biopsy.

Kormazer E et al reported that thirty women had irregular endometrium by hysteroscopic impression; 10 of them had simple endometrial hyperplasia, 1 of them had EIN and 2 of them had endometrial carcinoma in pathological assessment. ${ }^{8}$ Hysteroscopy diagnosed all intrauterine space occupying lesions (76 endometrial polyp, 17 submucosal fibroid) but D and C missed 25 of these women (atrophy). Alanis Fuentes $\mathrm{J}$ et al, correlated results between hysteroscopic findings and histopathological biopsy diagnosis obtained were: atrophy (157 cases, 63.3\%), polyps (76 cases, $77.55 \%$ ), endometrial cancer (14 cases, 93.05\%), endometrial hyperplasia (10 cases, 90.63\%) and miomatosis (three cases, $16.20 \%){ }^{9}$

The sensitivity, specificity, positive predictive value, negative predictive value and diagnostic accuracy of hysteroscopy in diagnosing malignancy was $75 \%$, $96.15 \%, 75 \%, 96.15 \%$ and $93.33 \%$ respectively. Elfayomy A et al reported that in benign endometrial lesions, the sensitivity of the hysteroscopic view was $94.7 \%$, specificity was $97.8 \%$, positive (PPV) and negative (NPV) predictive values were 97.3 and $95.7 \%$, respectively. $^{7}$ On the other hand, hysteroscopy demonstrated an overall sensitivity, specificity, PPV, and NPV of 56.5, 91.6, 72.2, and $84.6 \%$, respectively, in endometrial hyperplasia, whereas the same parameters for endometrial cancer were 50, 94.2, 63.6, and 90.2\% Dinic $\mathrm{P}$ et al, conducted a study to define the significance of hysteroscopy as a diagnostic procedure for the evaluation of patients with postmenopausal bleeding. ${ }^{10}$ The sensitivity of hysteroscopy in the detection of intrauterine pathology was $100 \%$, the specificity $81 \%$, the positive predictive value $92 \%$ and the negative predictive value $100 \%$.

Loiacono $\mathrm{R}$ et al, conducted a study compares hysteroscopic and histo-pathological results in postmenopausal women with abnormal uterine bleeding (AUB) and asymptomatic postmenopausal women with a thickened endometrium. ${ }^{11}$ In the AUB group, if the hysteroscopy results were normal, a sensitivity, specificity, positive predictive value (PPV) and negative predictive value (NPV) of 100, 95, 71 and 100\%, respectively, were achieved, while in the asymptomatic group these values were 100, 97, 90 and 100\%, respectively. For both the group with polyps and that with myomas, the sensitivity, specificity, PPV and NPV were $100 \%$. For endometrial hyperplasia, hysteroscopy showed sensitivity, specificity, PPV and NPV of $81,96,87$ and 93\%, respectively, in the AUB group, while in the asymptomatic group, the sensitivity was $60 \%$, the specificity and PPV were $100 \%$, and the NPV was $98 \%$. The sensitivity of hysteroscopy for endometrial cancer was $63 \%$, the specificity $97 \%$, the PPV $77 \%$, and the
NPV 95\%. Tinelli R et al, inferred that hysteroscopy was technically successful in all women and revealed sensitivity of $98 \%$, specificity of $91 \%$, a positive predictive value of $88 \%$, a negative predictive value of $98 \%$, and diagnostic accuracy of $94 \% .^{12}$

Garuti $\mathrm{G}$ et al, reported that the sensitivity, specificity, and negative and positive predictive values of hysteroscopy to foresee a diagnosis of infiltrating carcinoma were $84.6 \%, 100 \%, 87.5 \%$, and $100 \%$, respectively. ${ }^{13}$ Kormazer $\mathrm{E}$ et al, reported that the hysteroscopy revealed sensitivity, specificity, positive predictive value and negative predictive value as $76.4 \%$, $76.9 \%, 73.1 \%, 79.8 \%$, respectively. ${ }^{8}$ Sarvi $\mathrm{F}$ et al, conducted a study to investigate the histologic and hysteroscopic findings of post-menopausal women with uterine bleeding. ${ }^{14}$

In the AUB group sensitivity, specificity, and positive and negative predictive values of hysteroscopy for normal findings were 98\%, 100\%, 100\% and 90\%, respectively. In the asymptomatic group, the same parameters were $98 \%, 100 \%, 100 \%$ and $85 \%$, respectively. The sensitivity, specificity, and positive and negative predictive values of hysteroscopy for polyps and myomas were $100 \%$. Also, the sensitivity, specificity, and positive and negative predictive values were $100 \%$ in hyperplasia cases found during hysteroscopy in both groups. Kanani $\mathrm{K}$ et al, conducted a study the hysteroscopic evaluation of abnormal uterine bleeding in reproductive and post-menopausal women. ${ }^{15}$ Comparison of hysteroscopic and histopathologic results show that the sensitivity of hysteroscopy in detection of intrauterine pathology was $95.4 \%$, specificity $96.4 \%$, positive predictive value was $95.4 \%$ and the negative predictive value was $96.4 \%$.

Valson $\mathrm{H}$ et al, conducted a study hysteroscopic evaluation of abnormal uterine bleeding in reproductive and post-menopausal women. ${ }^{16}$ Both hysteroscopy and (D and C) were accurate when an abnormality was diagnosed, giving a specificity of $96.4 \%$ and $96.4 \%$ respectively and positive predictive value of $(95.2 \%$ versus $94.4 \%$ ). The ability to diagnose a lesion was more with hysteroscopy i.e. sensitivity in comparison to curettage, (90.9\% versus $77.4 \%$ ), while a negative diagnosis was less wrongly made with hysteroscopy in comparison to curettage (false negative rate: $9.1 \%$ versus $22.7 \%$ ). In intracavitary lesions like polyp, hysteroscopy gave $100 \%$ accuracy.

\section{CONCLUSION}

To conclude the most common cause of abnormal uterine bleeding in post-menopausal women in our study was polyp. The sensitivity and specificity of the hysteroscopy in diagnosing the malignant lesions is $75 \%$ and $96.15 \%$ respectively which corroborated with other study findings. Hysteroscopy with dilation and curettage is 
better alternative to hysterectomy and biopsy in most of the cases.

Funding: No funding sources

Conflict of interest: None declared

Ethical approval: The study was approved by the Institutional Ethics Committee

\section{REFERENCES}

1. Whitaker L, Critchley HOD. Abnormal uterine bleeding. Best Pract Res Clin Obstet Gynaecol. 2016;34:54-65.

2. Goldstein SR. Abnormal uterine bleeding: the role of ultrasound. Radiol Clin North Am. 2006;44(6):90110.

3. Su H, Huang L, Huang KG, Yen CF, Han CM, Lee CL. Accuracy of hysteroscopic biopsy, compared to dilation and curettage, as a predictor of final pathology in patients with endometrial cancer. Taiwan J Obstet Gynecol. 2015;54(6):757-60.

4. Sinha P, Yadav N, Gupta U. Use of hysteroscopy in abnormal uterine bleeding: an edge over histopathological examination. J Obstet Gynaecol India. 2018;68(1):45-50.

5. Pandey VK, Aggarwal P, Kakkar R. Modified BG Prasad socio-economic classification, Update-2019. Indian J Community Heal. 2019;31(1):150-2.

6. World Health Organization guidelines for classification of anaemia, 2014. Available at: https://www.who.int/vmnis/indicators/haemoglobin.p df. Accessed on $10^{\text {th }}$ January 2020.

7. Elfayomy AK, Habib FA, Alkabalawy M. Role of hysteroscopy in the detection of endometrial pathologies in women presenting with postmenopausal bleeding and thickened endometrium. Arch Gynecol Obs. 2012;285:839-43.

8. Korkmazer E, Solak N, Üstünyurt E. Hysteroscopic assessment of postmenopausal endometrial thickening. Prz Menopauzalny. 2014;13(6):330-3.

9. Alanis Fuentes J, Martinez Gutlerrez M, Mata M. Hysteroscopy findings in patients with postmenopausal genital bleeding. Ginecol Obs Mex. 2007;75(5):253-8.
10. Dinic P, Ljubic A, Kopitovic V, Antic V, Stamenovic S, Pjevic A. The role of hysteroscopy in diagnosis and treatment of postmenopausal bleeding. Vojn Pregl. 2013;70(8):1-2.

11. Loiacono R, Trojano G, Gaudio N, Kardhashi A, Deliso M, Gaetano F, et al. Novel insights from clinical practice hysteroscopy as a valid tool for endometrial pathology in patients with postmenopausal bleeding or asymptomatic patients with a thickened endometrium: hysteroscopic and histological results. Gynecol Obs Invest. 2015;79:210-6.

12. Tinelli R, Tinelli FG, Cicinelli E, Malvasi A, Tinelli A. The role of hysteroscopy with eye-directed biopsy in postmenopausal women with uterine bleeding and endometrial atrophy. Menopause. 2008;15(4):73742.

13. Garuti G, Mirra M, Luerti M. Hysteroscopic view in atypical endometrial hyperplasias: a correlation with pathologic findings on hysterectomy specimens. J Minim Invasive Gynecol. 2006;13:325-30.

14. Sarvi F, Alleyassin A, Aghahosseini M, Ghasemi M, Gity S. Hysteroscopy: a necessary method for detecting uterine pathologies in post-menopausal women with abnormal uterine bleeding or increased endometrial thickness Histeroskopi. Turk J Obs Gynecol. 2016;13:183-8.

15. Kanani K, Panchal P, Shah S, Mehta A, Bhagde A. Evaluation of abnormal uterine bleeding by hysteroscopy and curettage. Int $\mathbf{J}$ Sci Res. 2017;6(8):417-9.

16. Valson H, Kulkarni C, Mukerjee S, Gowda SN, Valson H, Contracept JR, et al. The role of diagnostic hysteroscopy in abnormal uterine bleeding and its histopathological correlation following blind dilatation and curettage. Int J Reprod Contracept Obs Gynecol. 2016;5(3):609-14.

Cite this article as: Padmawar A, Khande A. Study of the role of hysteroscopy with dilation and curettage in post-menopausal bleeding: a cross sectional study. Int J Reprod Contracept Obstet Gynecol 2020;9:1954-8. 